\title{
Prevalence of Hypoglycaemia in Newborn at Benue State University Teaching Hospital, Makurdi, Benue State, Nigeria
}

\author{
Martha Omoo Ochoga ${ }^{*}$, Michael Aondoaseer', Rose Okwunu Abah1, Onyilo Ogbu1, \\ Emeka Uba Ejeliogu2 ${ }^{2}$, Geoffrey Ingyoroko Tolough ${ }^{3}$ \\ ${ }^{1}$ Department of Paediatrics, Benue State University Teaching Hospital, Makurdi, Nigeria \\ ${ }^{2}$ Department of Pediatrics, University of Jos, Nigeria \\ ${ }^{3}$ Department of Epidemiology and Community Health, College of Health Sciences, Benue State University, Makurdi, Nigeria \\ Email: *ochogamartha@gmail.com, aseemyam@gmail.com, abahplc@yahoo.com, onyiloogbu@yahoo.com, \\ emekam12@yahoo.com,drtolough@yahoo.com
}

How to cite this paper: Ochoga, M.O., Aondoaseer, M., Abah, R.O., Ogbu, O., Ejeliogu, E.U. and Tolough, G.I. (2018) Prevalence of Hypoglycaemia in Newborn at Benue State University Teaching Hospital, Makurdi, Benue State, Nigeria. Open Journal of Pediatrics, 8, 189-198. https://doi.org/10.4236/ojped.2018.82021

Received: May 14, 2018

Accepted: June 18, 2018

Published: June 21, 2018

Copyright (c) 2018 by authors and Scientific Research Publishing Inc. This work is licensed under the Creative Commons Attribution International License (CC BY 4.0).

http://creativecommons.org/licenses/by/4.0/

\begin{abstract}
Background: Neonatal hypoglycaemia is the most common metabolic abnormality in neonates and is associated with neurological damage and death when it occurs during the first few days of life. The main objective of this study was to determine the prevalence of hypoglycaemia in the newborn and the associated maternal/neonatal risk factors. Setting and Methods: This prospective descriptive study was conducted at the labour room and the Special Care Baby Unit of Benue State University Teaching Hospital, Makurdi, Benue State, Nigeria, between July 2017-March 2018. Results: Of the 168 neonates, $140(83.3 \%)$ were delivered in the hospital and $28(16.7 \%)$ were delivered outside the hospital. Hypoglycaemia was found in 19 (11.0\%) of the neonates. The mean (standard deviation) of gestational age was 37.8 (3.0) weeks. $91(54.2 \%)$ were males and $77(45.8 \%)$ were females. Male to female ratio is 1.2:1. A significantly higher proportion of $9(32.1 \%)$ out born compared with $10(7.1 \%)$ of inborn, 4 (44.4\%) of birth < $1500 \mathrm{~g}$ compared with $5(22.7 \%)$ birth weight $1500 \mathrm{~g}-2499 \mathrm{~g}$ and $10(7.3 \%)$ of birth weight $\geq 2500 \mathrm{~g}$ and 7 (22.6\%) of babies with temperature $\leq 36.5^{\circ} \mathrm{C}$ compared with 7 (6.3\%) of temperature $36.5^{\circ} \mathrm{C}-37.5^{\circ} \mathrm{C}$ and $5(19.2 \%)$ of temperature $>37.5^{\circ} \mathrm{C}$, demonstrated hypoglycaemia respectively. Neonatal risk factors, such as, prematurity, low birth weight and respiratory distress syndrome, were significantly associated with hypoglycaemia p-value of $0.02,0.01$ and 0.00 respectively. There were no statistically significant associations between maternal risk factors and hypoglycaemia. The common presenting symptoms were jitteriness, cyanosis, tachypnoea, hypotonia, apnoea, temperature instability, seizure and lethargy. Conclusion: The prevalence of hypoglycaemia was $11.0 \%$ in the present
\end{abstract}


study. Gestational age, low birth weight and respiratorty distress were risk factors documented for neonatal hypoglycaemia. The maternal risk factors associated with hypoglycaemia in the present study were not statistically significant. The commonest clinical manifestations of neonatal hypoglycaemia were tachypnoea and seizures.

\section{Keywords}

Neonatal Hypoglycaemia, Prevalence, Risk Factors, Clinical Manifestations

\section{Introduction}

Neonatal hypoglycaemia is important because it is the most common metabolic abnormality in neonates and is associated with neurological damage and death when it occurs during the first few days of life [1]. It is defined either as whole blood glucose of less than $2.2 \mathrm{mmol} / \mathrm{L}$ or plasma glucose of less than or equal to $2.5 \mathrm{mmol} / \mathrm{L}$ [2]. Neonatal hypoglycaemia affects $5 \%$ to $15 \%$ of otherwise healthy babies [2] [3] and is widespread in resource poor countries [4] [5]. About $8 \%$ of large for gestational age infants and $15 \%$ of preterm infants and infants who have intrauterine growth retardation (IUGR) have been reported as having hypoglycaemia. The incidence in the entire population of high risk infants may be as high as $30 \%$ [6]. Prevalence of hypoglycaemia is increasing because of the increasing incidence of preterm birth [7] and maternal factors, such as diabetes [8] and obesity [9], which can predispose babies to hypoglycaemia.

The symptomatic response of the neonate to low blood glucose is variable with non-specific clinical features including pallor, feeding difficulties, tachypnea, hypotonia, abnormal cry, jitteriness, apnea, coma and convulsions. Moderate asymptomatic hypoglycaemia should first be treated by adjusting the enteral feeding regimen. If this approach fails, intravenous therapy should be instituted when facilities are available. Studies have been done on neonatal hypoglycaemia in other parts of Nigeria [4] [5], but there has been no previous documentation on the prevalence of neonatal hypoglycaemia at Benue State University Teaching Hospital, Makurdi, Benue State. The present study was therefore undertaken to determine the prevalence of hypoglycaemia in the newborn, and the associated maternal/neonatal risk factors.

\section{Patients and Methods}

This prospective descriptive study was conducted at the labour room and the Special Care Baby Unit (SCBU) of the Benue State University Teaching Hospital (BSUTH), Makurdi, Benue State over a nine month period. All consecutive neonates delivered in the labour room and admitted into the SCBU within the first 24 hours of life were recruited into the study. The babies whose parents refused to give consent and those who have had intravenous infusion of fluid(s) were excluded from the study. A minimum sample size of 150.4 was arrived at 
using the formula $\left[n=z^{2} p(1-p) / d^{2}\right][10]$, based on the assumption of neonatal hypoglycaemia rate of $11.0 \%$ from a previous study [11], and $5 \%$ degree of precision at $95 \%$ confidence interval. Considering attrition rate of $10 \%$, the calculated sample size was adjusted to 168 . Blood glucose was estimated on all the babies delivered in the labour room and those admitted into the SCBU after obtaining informed consent from the mother. Ethical clearance was obtained from the Ethical and Research Committee of the hospital. A research proforma was administered to every recruited patient. Neonates age, sex, place of birth, gestational age assessed according to the new Ballard scoring system, birth weight, temperature, maternal and neonatal risk factors for hypoglycaemia and the clinical manifestations of hypoglycaemia were recorded.

Random blood sugar level on each patient was estimated at birth or on admission, using standard laboratory methods. The first post natal glucose testing was performed within the first 24 hours of life. The blood glucose level of $<2.2$ $\mathrm{mmol} / \mathrm{l}$ was considered hypoglycaemic. Testing of neonatal glucose was performed using Accu-Check Active 07124112 glucometer. The glucometer strips were inserted into the meter and when the meter started blinking. Blood was applied to the test area on the strip. All babies with hypoglycaemic convulsions, were given a bolus of $4 \mathrm{ml} / \mathrm{kg}$ of $10 \%$ dextrose water, followed by continious glucose infusion of 4 to $6 \mathrm{mg} / \mathrm{kg} / \mathrm{min}$ for full term infants and 6 to $8 \mathrm{mg} / \mathrm{kg} / \mathrm{min}$ for premature infants. Other symptomatic infants were given intravenous $10 \%$ dextrose water $2 \mathrm{ml} / \mathrm{kg}$ bolus followed by the continious infusion of $10 \% \mathrm{dex}$ trose water until the patient fully recovered. Data was analyzed using Statistical Package for the Social Sciences (SPSS) version 20. Descriptive statistics were generated for each study variable including frequencies and percentages for categorical variables, mean and standard deviation for continuous variables. Chi-square was used to test association between categories of the dimensions and socio-demographic, maternal risk factors, neonatal risk factors and signs of hypoglycaemia. Level of statistical significance was set at $5 \%$.

\section{Results}

Of the 168 neonates, $140(83.3 \%)$ were delivered in the hospital and $28(16.7 \%)$ were delivered outside the hospital. Hypoglycaemia was found in 19 (11.0\%) of the neonates at the time of admission (Figure 1). The mean (standard deviation) of gestational age was 37.8 (3.0) weeks with a proportion of 131 (78.0\%) having greater or equal to thirty-seven weeks, 25 (14.9\%) had gestational age thirtythree to thirty-six weeks, while $12(7.1 \%)$ had less than or equal to thirty-two weeks. Of the 168 babies, 91 (54.2\%) were males and 77 (45.8\%) were females. Male to female ratio is $1.2: 1$. The median birth weight was $3200 \mathrm{~g}$ with a higher proportion of 137 (81.5\%) who had birth weight $\geq 2500 \mathrm{~g}$. The mean (SD) of temperature was $36.8^{\circ} \mathrm{C}(1.01)$ with a higher proportion of $111(66.1 \%)$ having normal temperature (Table 1 ).

As shown in Figure 1, the prevalence of hypoglycaemia among neonates was $11 \%$. 


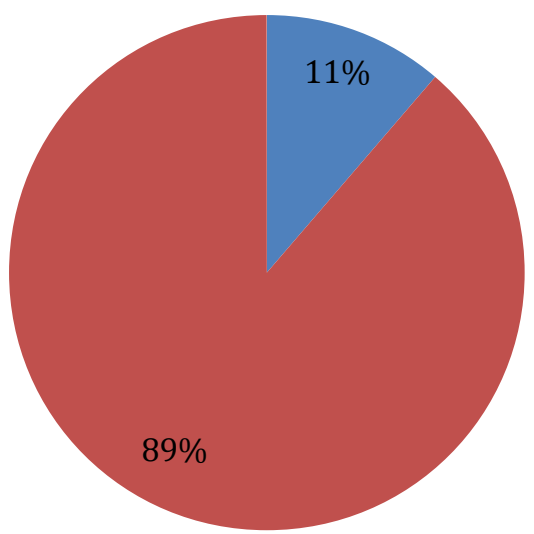

- Hypoglycaemia

Normal

Figure 1. Prevalence of Hypoglycaemia.

Table 1. Baseline characteristics of babies with and without hypoglycaemia.

\begin{tabular}{|c|c|c|}
\hline Characteristics & Frequency & Percent \\
\hline \multicolumn{3}{|l|}{ Receiving status } \\
\hline Inborn & 140 & 83.3 \\
\hline Outborn & 28 & 16.7 \\
\hline \multicolumn{3}{|c|}{ Gestational age (in weeks) } \\
\hline$\leq 32$ & 12 & 7.1 \\
\hline $33-36$ & 25 & 14.9 \\
\hline$\geq 37$ & 131 & 78.0 \\
\hline \multicolumn{3}{|l|}{ Mean $37.83 \pm 2.98$} \\
\hline \multicolumn{3}{|l|}{ Sex } \\
\hline Male & 91 & 54.2 \\
\hline Female & 77 & 45.8 \\
\hline \multicolumn{3}{|c|}{ Birth weight (in grams) } \\
\hline$<1500$ & 9 & 5.4 \\
\hline $1500-2499$ & 22 & 13.1 \\
\hline$\geq 2500$ & 137 & 81.5 \\
\hline \multicolumn{3}{|l|}{ Median 3200} \\
\hline \multicolumn{3}{|l|}{ Temperature $\left({ }^{\circ} \mathrm{C}\right)$} \\
\hline$\leq 36.5$ & 31 & 18.5 \\
\hline $36.5-37.5$ & 111 & 66.0 \\
\hline$>37.5$ & 26 & 15.5 \\
\hline Mean $36.8 \pm 1.01$ & & \\
\hline
\end{tabular}

As shown in Table 2, a higher proportion of the out born newborns compared with the inborn newborns experienced hypoglycaemia and this was statistically significant $(\mathrm{p}=0.000)$. There was no significant association between gestational age and hypoglycaemia. Hypoglycaemia was more among very low birth weight babies (44.4\%) compared to the other birth weight groups and this was statistically significant $(\mathrm{p}=0.002)$. Hypoglycaemia was recorded among newborns with temperature $\leq 36.5$ and when compared to the other temperature group was statistically significant $(\mathrm{p}=0.010)$. 
Table 2. Association of baseline characteristics and hypoglycaemia.

\begin{tabular}{cccccc}
\hline \multicolumn{1}{c}{ Babies with } & $\begin{array}{c}\text { Babies without } \\
\text { Hypoglycaemia } \\
(\%)\end{array}$ & $\begin{array}{c}\text { Hypoglycaemia } \\
(\%)\end{array}$ & Test statistics & df p-value \\
\hline Variables & $10(7.1)$ & $130(92.9)$ & Continuity & 1 & 0.000 \\
Receiving status & correction $=12.15$ & \\
Inborn & $9(32.1)$ & $19(67.9)$ & & & \\
Outborn & $4(33.3)$ & $8(66.7)$ & Fisher's & 2 & 0.071 \\
Gestational age (in weeks) & $2(8.0)$ & $23(92.0)$ & exact $=5.15$ & & \\
$\leq 32$ & $13(9.9)$ & $118(90.1)$ & & & \\
$33-36$ & $11(12.1)$ & $80(87.9)$ & $\chi^{2}=0.12$ & 1 & 0.729 \\
$\geq 37$ & $8(10.4)$ & $69(89.6)$ & & & \\
Sex & $4(44.4)$ & $5(55.6)$ & Fisher's & 2 & 0.002 \\
Male & $5(22.7)$ & $17(77.3)$ & exact $=12.20$ & & \\
Female & $10(7.3)$ & $127(92.7)$ & & & \\
Birth weight (in grams) & $7(22.6)$ & $24(77.4)$ & Fisher's & 2 & 0.010 \\
$<1500$ & $7(6.3)$ & $104(93.7)$ & exact $=8.31$ & & \\
$1500-2499$ & $5(19.2)$ & $21(80.8)$ & & &
\end{tabular}

Table 3 shows that prematurity, low birth weight, small for gestational age, large for gestational age, jaundice, severe birth asphyxia, moderate birth asphyxia, respiratory distress, congenital heart disease and inadequate feeding were risk factors for hypoglycaemia in neonates. Hypoglycaemia was significantly more frequent among neonates with prematurity and respiratory distress and this was statistically significant with $\mathrm{p}<0.05$.

Table 4 presents the association between maternal risk factors and hypoglycaemia. Maternal risk factors hypertension, diabetes, intrapartum administration of glucose and the use of beta blockers had no significant association with the development of hypoglycaemia amongst the neonates.

Table 5 shows the distribution of the clinical manifestations of hypoglycaemia among the newborns with and without hypoglycaemia. Hypoglycaemia was significantly associated with tachypnoea and seizure. Cyanosis, tachypnoea, apnoea, temperature instability, seizures and lethargy were identified in hypoglycaemic as well as non-hypoglycaemic newborns.

\section{Discussion}

The prevalence of neonatal hypoglycaemia in the present study was 11.0 percent, much lower than the 28.3 percent reported from Port Harcourt by Frank-Briggs [4] and 32.7 percent by Dedeke et al. [5]. This is comparable to 9.5 percent reported by Njokanma and Fagbule [12] and 6.6 percent by Omene in Benin [13]. Our study showed that more males were affected than females and consistent with other studies [14] [15]. However, being a male is not a risk factor for hypoglycaemia. In the present study, neonates with birth weight $\geq 2500 \mathrm{~g}$ at birth 
Table 3. Association of neonatal risk factors and hypoglycaemia.

\begin{tabular}{|c|c|c|c|c|c|c|}
\hline Risk Factors & $\begin{array}{c}\text { Babies with Hypoglycaemia } \\
\text { N (\%) }\end{array}$ & $\begin{array}{c}\text { Babies without } \\
\text { Hypoglycaemia N\%) }\end{array}$ & Total N (\%) & Test statistics & df & p-value \\
\hline \multicolumn{7}{|l|}{ Prematurity } \\
\hline Yes & $7(25.9)$ & $20(74.1)$ & $27(16.1)$ & Continuity correction $=5.23$ & 1 & 0.022 \\
\hline No & $12(8.5)$ & $129(91.5)$ & $141(83.9)$ & & & \\
\hline \multicolumn{7}{|c|}{ Low Birth Weight } \\
\hline Yes & $7(26.9)$ & $19(73.1)$ & $26(15.5)$ & Continuity correction $=5.75$ & 1 & 0.017 \\
\hline No & $12(8.5)$ & $130(91.5)$ & $142(84.5)$ & & & \\
\hline \multicolumn{7}{|c|}{ Small for Gestational Age } \\
\hline Yes & $2(28.6)$ & $5(71.4)$ & $7(4.2)$ & Continuity correction $=0.75$ & 1 & 0.388 \\
\hline No & $17(10.6)$ & $144(89.4)$ & $161(95.8)$ & & & \\
\hline \multicolumn{7}{|c|}{ Large for Gestational Age } \\
\hline Yes & $2(20.0)$ & $8(80.0)$ & $10(6.0)$ & Continuity correction $=0.14$ & 1 & 0.704 \\
\hline No & $17(10.8)$ & $141(89.2)$ & $158(94.0)$ & & & \\
\hline \multicolumn{7}{|l|}{ Jaundice } \\
\hline Yes & $1(25.0)$ & $3(75.0)$ & $4(2.4)$ & Continuity correction $=0.01$ & 1 & 0.939 \\
\hline No & $18(11.0)$ & $146(89.0)$ & $164(97.6)$ & & & \\
\hline \multicolumn{7}{|c|}{ Severe Birth Asphyxia } \\
\hline Yes & $1(14.3)$ & $6(85.7)$ & $7(4.2)$ & Continuity correction $=0.00$ & 1 & 1.000 \\
\hline No & $18(11.2)$ & $143(88.8)$ & $161(95.8)$ & & & \\
\hline \multicolumn{7}{|c|}{ Moderate Birth Asphyxia } \\
\hline Yes & $1(33.3)$ & $2(66.7)$ & $3(1.8)$ & Continuity correction $=0.09$ & 1 & 0.768 \\
\hline No & $18(10.9)$ & $147(89.1)$ & $165(98.2)$ & & & \\
\hline \multicolumn{7}{|c|}{ Respiratory distress } \\
\hline Yes & $7(41.2)$ & $10(58.8)$ & $17(10.1)$ & Continuity correction $=13.67$ & 1 & 0.000 \\
\hline No & $12(7.9)$ & $139(92.1)$ & $151(89.9)$ & & & \\
\hline \multicolumn{7}{|l|}{ NNS } \\
\hline Yes & $3(20.0)$ & $12(80.0)$ & $15(8.9)$ & Continuity correction $=0.47$ & 1 & 0.492 \\
\hline No & $16(10.5)$ & $137(89.5)$ & $153(91.1)$ & & & \\
\hline \multicolumn{7}{|c|}{ Congential Heart Disease } \\
\hline Yes & $0(0.0)$ & $1(100.0)$ & $1(0.6)$ & Continuity correction $=0.00$ & 1 & 1.000 \\
\hline No & $19(11.4)$ & $148(88.6)$ & $167(99.4)$ & & & \\
\hline \multicolumn{7}{|c|}{ Inadequate feeding } \\
\hline Yes & $4(26.7)$ & $11(73.3)$ & $15(8.9)$ & Continuity correction $=2.37$ & 1 & 0.123 \\
\hline No & $15(9.8)$ & $138(90.2)$ & $153(91.1)$ & & & \\
\hline
\end{tabular}

Note: $54.8 \%$ are without risk factors.

Table 4. Association of maternal risk factors and blood glucose.

\begin{tabular}{|c|c|c|c|c|c|c|}
\hline Variables & $\begin{array}{c}\text { Babies with } \\
\text { Hypoglycaemia } \\
\text { N (\%) }\end{array}$ & $\begin{array}{c}\text { Babies without } \\
\text { Hypoglycaemia } \\
\text { N (\%) }\end{array}$ & $\begin{array}{l}\text { Total } \\
\text { N (\%) }\end{array}$ & Test statistics & df & $\mathrm{p}$-value \\
\hline \multicolumn{7}{|c|}{ Maternal Hypertension } \\
\hline Yes & $2(18.2)$ & $9(81.8)$ & $11(6.5)$ & & & \\
\hline No & $17(10.8)$ & $140(89.2)$ & $157(93.5)$ & Continuity correction $=0.55$ & 1 & 0.801 \\
\hline \multicolumn{7}{|c|}{ Maternal Diabetes } \\
\hline Yes & $0(0.0)$ & $1(100.0)$ & $1(0.6)$ & & & \\
\hline No & $19(11.4)$ & $148(88.6)$ & $167(99.4)$ & Continuity correction $=0.00$ & 1 & 1.000 \\
\hline \multicolumn{7}{|l|}{ Intrapartum } \\
\hline \multicolumn{7}{|c|}{ Administration of Glucose } \\
\hline Yes & $2(13.3)$ & $13(86.7)$ & $15(8.9)$ & & \multirow{2}{*}{1} & \multirow{2}{*}{1.000} \\
\hline No & $17(11.1)$ & $136(88.9)$ & $153(91.1)$ & Continuity correction $=0.00$ & & \\
\hline \multicolumn{7}{|l|}{ Beta Blockers } \\
\hline Yes & $0(0.0)$ & $3(100.0)$ & $3(1.8)$ & & & \multirow{2}{*}{0.704} \\
\hline No & $19(11.5)$ & $146(88.5)$ & $165(98.2)$ & Continuity correction $=0.00$ & 1 & \\
\hline
\end{tabular}

Note: $82.7 \%$ are without risk factors. 
Table 5. Comparism of Clinical manifestations of hypoglycaemia among babies with and without hypoglycaemia.

\begin{tabular}{|c|c|c|c|c|c|c|}
\hline $\begin{array}{c}\text { Clinical } \\
\text { Manifestation }\end{array}$ & $\begin{array}{c}\text { Babies with } \\
\text { Hypoglycaemia } \\
\text { N (\%) }\end{array}$ & $\begin{array}{c}\text { Babies without } \\
\text { Hypoglycaemia } \\
\text { N (\%) }\end{array}$ & $\begin{array}{l}\text { Total } \\
\text { N (\%) }\end{array}$ & Test statistics & df & p-value \\
\hline \multicolumn{7}{|l|}{ Jitteriness } \\
\hline Yes & $0(0.0)$ & $3(100.0)$ & $3(1.8)$ & Continuity correction $=0.00$ & 1 & 1.000 \\
\hline No & $19(11.5)$ & $146(88.5)$ & $165(98.2)$ & & & \\
\hline \multicolumn{7}{|l|}{ Cyanosis } \\
\hline Yes & $1(25.0)$ & $3(75.0)$ & $3(2.4)$ & Continuity correction $=0.00$ & 1 & 0.939 \\
\hline No & $18(11.0)$ & $146(89.0)$ & $164(97.6)$ & & & \\
\hline \multicolumn{7}{|l|}{ Tachypnoea } \\
\hline Yes & $3(42.9)$ & $4(57.1)$ & $7(4.2)$ & Continuity correction $=4.34$ & 1 & 0.037 \\
\hline No & $16(9.9)$ & $145(90.1)$ & $161(95.8)$ & & & \\
\hline \multicolumn{7}{|l|}{ Hypotonia } \\
\hline Yes & $0(0.0)$ & $1(100.0)$ & $1(0.6)$ & Continuity correction $=0.00$ & 1 & 1.000 \\
\hline No & $19(11.4)$ & $148(88.6)$ & $167(99.4)$ & & & \\
\hline \multicolumn{7}{|l|}{ Apnoea } \\
\hline Yes & $2(40.0)$ & $3(60.0)$ & $5(3.0)$ & Continuity correction $=1.80$ & 1 & 0.180 \\
\hline No & $17(10.4)$ & $146(89.6)$ & $163(97.0)$ & & & \\
\hline \multicolumn{7}{|c|}{ Temperature instability } \\
\hline Yes & $4(22.2)$ & $14(77.8)$ & $18(10.7)$ & Continuity correction $=1.33$ & 1 & 0.249 \\
\hline No & $15(10.0)$ & $135(90.0)$ & $150(89.3)$ & & & \\
\hline \multicolumn{7}{|l|}{ Seizure } \\
\hline Yes & $4(100.0)$ & $0(0.0)$ & $4(2.4)$ & Continuity correction $=23.71$ & 1 & 0.000 \\
\hline No & $15(9.1)$ & $149(90.9)$ & $164(97.6)$ & & & \\
\hline \multicolumn{7}{|l|}{ Lethargy } \\
\hline Yes & $2(40.0)$ & $3(60.0)$ & $5(3.0)$ & Continuity correction $=1.80$ & 1 & 0.180 \\
\hline No & $17(10.4)$ & $146(89.6)$ & $163(97.0)$ & & & \\
\hline
\end{tabular}

were more than the other birth weight groups and this may have accounted for the lower prevalence of hypoglycaemia. The highest prevalence of hypoglycaemia was 44.4 percent among babies with very low birth weight (VLBW) and this was followed by 33.3 percent in very preterm babies and was statistically significant with $\mathrm{p}=0.002$. Our findings are consistent with that reported by other workers [12] [16] [17] but higher than that reported by Pildes and Pyati [18].

In this study hypoglycaemia was found in a higher proportion amongst the outborn babies as compared to the inborn babies. This finding is comparable to that reported by Dedeke, Njokanma and Fagbule [5] [12]. This could be as a result of delay in presentation of the outborn babies to the hospital and as a result of the babies being subjected to cold injury during transfer. The ideal method of transporting the babies is by use of transport incubators or proper wrappings. The lower prevalence rate among the inborn could be as a result of a high index of suspicion and better high risk neonate identification and interventions. Fu- 
ther more since the patients were managed in the hospital, intrapartum conditions were better handled and that may reduce fetal distress and other related conditions that may predispose the babies to hypoglycaemia.

The maternal risk factors identified in the present study were maternal hypertension and intrapartum administration of glucose but were not statistically significant. Omene [13] also did not report any significant association with toxaemic mothers. This contrasts with the occurrence of hypoglycaemia in over half of infants of toxaemic mothers in other series [19] [20]. Toxaemia of pregnancy among West Africans commonly take the acute form compared to the more chronic pattern observed among Europeans [21]. Hypoglycaemia is a common finding among infants of diabetic mothers [22]. This was not reported in our study. Dedeke [5] and Omene [13] did not observe hypoglycaemia among infants of diabetic mothers. The probable reason could have been as a result of proper management of diabetes in pregnancy.

Preterm babies have low glycogen stores and as a result are more predisposed to hypoglycaemia [23]. In this study 25.9 perecent neonates with hypoglycaemia were preterms. Prematurity was a significant risk factor for hypoglycaemia and similar to what was reported by Ayoub [14] and Dedeke [5]. Hypothermia was detected in 22.6 percent of the neonates and was a significant risk factor for hypoglycaemia, probabaly due to increased glucose utilization. This is at variance to the findings of Ayoub [14] where they attributed their own results to the small number of sample taken during the study. Other conditions found in the hypoglycaemic neonates were low birth weight 25.9 percent and respiratory distress 41.2 percent. These results compare with other studies [12] [15].

In the present study the clinical manifestation of neonates with hypoglycaemia are similar to those reported in literature. Neonates manifested clinical features that are usually associated with hypoglycaemia [13] and this comprised cyanosis 25.0 percent, tachypnoea 42.9 percent, apnoea 40.0 percent, temperature instability 22.2 percent seizures 100.0 percent and lethargy 40.0 percent of the cases. Njokanma et al. reported similar findings [12]. There was no case of jitteriness observed in our study as compared to Omene in Benin reporting 20.0 percent [13]. The possible explanation for the observations could be that our neonates presented after onset of seizures, while the Benin patients presented earlier with jitteriness in the pre-convulsive stage. Dedeke however reported poor suck, cyanosis, convulsions and pallor as the commest manifestation of hypoglycaemia [5].

\section{Conclusion}

The prevalence of hypoglycaemia was $11.0 \%$ in the present study. Gestational age, low birth weight and respiratory distress were risk factors documented for neonatal hypoglycaemia. The maternal risk factors associated with hypoglycaemia in the present study were not statistically significant. The clinical manifestations of neonatal hypoglycaemia in the present study were tachypnoea and sei- 
zures.

\section{Funding}

The research was funded by the authors.

\section{Recommendations}

Blood glucose estimation should be routine in the care of high-risk neonates. There is need to train and retrain health care workers on the prevention of neonatal hypoglycaemia and provision of suitable transfer medium for referred cases should be intensified.

\section{Authors' Contributions}

All the authors: for the proof reading of this article; Ochoga, MO and Michael, A: for initiation, protocol drafting, data collection, writing of report and article draft; Abah, RO: report writing; Ogbu, O and Ejeliogu, EU: report writing.

\section{References}

[1] Kerstjens, J.M., Bocca-Tjeertes, I.F., de Winter, A.F., Reijneveld, S.A. and Bos, A.F. (2012) Neonatal Morbidities and Developmental Delay in Moderately Preterm-Born Children. Pediatrics, 130, 265-272.

https://doi.org/10.1542/peds.2012-0079

[2] Cornblath, M., Hawdon, J.M., Williams, A.F., Green-Aynsley, A., Wad-Platt, M.P., Schwartz, R., et al. (2000) Controversies regarding Definition of Neonatal Hypoglycaemia: Suggested Operational Thresholds. Pediatrics, 105, 1141-1145. https://doi.org/10.1542/peds.105.5.1141

[3] Hay, W.W., Raju, T., Higgins, R., Kalhan, S. and Devaskar, S. (2009) Knowledge Gaps and Research Needs for Understanding and Treating Neonatal Hypoglycaemia. Journal of Pediatrics, 155, 612-617. https://doi.org/10.1016/j.jpeds.2009.06.044

[4] Frank-Briggs, A.I., Ojule, A.C. and Nkanginieme, K.E. (2008) Neonatal Hypoglycaemia: Prevalence and Clinical Manifestations in Porth Harcourt, Nigeria. Port Harcourt Medical Journal, 2, 166-170.

[5] Dedeke, I.O.F., Okeniyi, J.A.O., Owa, J.A. and Oyedeji, G.A. (2011) Point-of-Admission Hypoglycaemia in a Nigerian Tertiary Hospital: Incidence, Risk Factors and Outcome. Nigerian Journal of Paediatrics, 38, 90-94. https://doi.org/10.4314/njp.v38i2.72252

[6] Williams, A.F. (1997) Hypoglycaemia in Newborn: A Review. Bulletin of the World Health Organization, 75, 261-290.

[7] Blencowe, H., Cousens, S., Oestergaard, M.Z., Chou, D., Moller, A.B. and Narwal, R. (2012) National, Regional, and Worldwide Estimates of Preterm Birth Rates in the Year 2010 with Time Trends since 1990 for Selected Countries: A Systematic Analysis and Implications. The Lancet, 379, 2162-2172. https://doi.org/10.1016/S0140-6736(12)60820-4

[8] Wild, S., Roglic, G., Green, A., Sicree, R. and King, H. (2004) Global Prevalence of Diabetes. Diabetes Care, 27, 1047-1053. https://doi.org/10.2337/diacare.27.5.1047

[9] Doherty, D.A., Magann, E.F., Francis, J., Morrison, J.C. and Newnham, J.P. (2006) Pre-Pregnancy Body Mass Index and Pregnancy Outcomes. International Journal of 
Obstetrics and Gynecology, 95, 242-247. https://doi.org/10.1016/j.ijgo.2006.06.021

[10] Taofeek, I. (2009) Research Methodology and Dissertation Writing for Health and Allied Health Professionals. 1st Edition, Cress Global Link Limited Publishers, Abuja, 70-75.

[11] Pal, D., Manandhar, D., Rajbhandari, S., Land, J., Patel, N. and Costello, A. (2000) Neonatal Hypoglycaemia in Nepal 1. Prevalence and Risk Factors. Archives of Disease in Childhood, Fetal and Neonatal Edition, 82, 46-51. https://doi.org/10.1136/fn.82.1.F46

[12] Njokanma, O.F. and Fagbule, D. (1994) Incidence, Aetiology and Manifestations of Neonatal Hypoglycaemia. Nigerian Journal of Paediatrics, 21, 26-31.

[13] Omene, J.A. (1977) The Incidence of Neonatal Hypoglycaemia in Benin. Nigerian Journal of Paediatrics, 4, 19-23.

[14] Ayoub, N.I., Hanoudi, B.M. and Naif, M.H. (2013) Evaluation of Maternal and Neonatal Risk Factors for Neonatal Hypoglycaemia. Iraqi Journal of Community Medicine, 1, 13-18.

[15] Bhand, S.A., Sheikh, F., Siyal, R.A., Nizamani, M.A. and Saeed, M. (2014) Neonatal Hypoglycaemia, Presenting Pattern and Risk Factors of Neonatal Hypoglycaemia. Professional Medical Journal, 21, 745-749.

[16] Fluge, G. (1974) Clinical Aspects of Neonatal Hypoglycaemia. Acta Paediatrica Scandinavica, 63, 826-832. https://doi.org/10.1111/j.1651-2227.1974.tb04871.x

[17] Lubchenco, L. and Bard, H. (1971) Incidence of Hypoglycaemia in Newborn Infants Classified by Birth Weight and Gestational Age. Pediatrics, 47, 831-838.

[18] Pildes, R.S. and Pyati, S.P. (1986) Hypoglycaemia and Hyperglycaemia in Tiny Infants. Clinics in Perinatology, 13, 351-375.

[19] Cornblath, M., Odell, G. and Levin, E.J. (1959) Symptomatic Neonatal Hypoglycaemia Associated with Toxaemia of Pregnancy. Journal of Pediatrics, 55, 545-562. https://doi.org/10.1016/S0022-3476(59)80239-0

[20] Cornblath, M. and Reisner, S.A. (1965) Blood Glucose in the Neonate and Its Clinical Significance. The New England Journal of Medicine, 273, 378-381. https://doi.org/10.1056/NEJM196508122730707

[21] Lawson, J.B. and Stewart, D.B. (1967) Obstertrics and Gynaecology in the Tropics and Developing Countries.1st Edition, Edward Arnold Ltd., London, 120-136.

[22] Deorari, A.K., Kabra, S.K., Paul, V.K. and Singh, M. (1991) Perinatal Outcome of Infants Born to Diabetic Mothers. Indian Pediatrics, 28, 1271-1275.

[23] Cornblath, M. and Schwartz, R. (2006) Hypoglycaemia in Neonate. Journal of Pediatric Endocrinology, 6, 113-129. 